\title{
Novel methods for inferring future changes in extreme rainfall over Northern Europe
}

\author{
Rasmus E. Benestad* \\ Norwegian Meteorological Institute, PO Box 43, 0313 Oslo, Norway
}

\begin{abstract}
Empirical studies show that observed frequencies $n_{P}$ for a daily precipitation amount $P$ can be approximated by $n_{P} \propto \mathrm{e}^{m P}$, with negative values for the exponential coefficient $m$. The parameter $m$ describes the mean $(\mu)$ or any quantile for variables following such exponential distributions. The coefficient $m$ varies from location to location, and exhibits a systematic relationship with local mean temperature and precipitation as well as other geographical parameters. A general linear model can be utilised to model $\mu$ directly from local climate conditions and geography. Estimates of $m$ and $\mu$ from local climatic conditions allow an estimation of extreme values in the form of high percentiles. Given changes in the mean local climate, it is possible to infer changes in the upper percentiles. A new multi-model ensemble of the most recent climate simulations, carried out for the Intergovernmental Panel on Climate Change fourth assessment report (IPCC AR4), has been subjected to empirical-statistical downscaling, and provides best estimates for the continuing trends in mean temperatures and precipitation in northern Europe. These scenarios are used in conjunction with (1) the established relationship between the exponential coefficient $m$ on the distribution function, and (2) local mean temperature and precipitation for 2050, to infer changes in the 95th percentiles of the rainfall for 2050. Two new independent analyses point towards an increase in the number of extreme precipitation events and a slight change in the number of rainy days over large parts of the Nordic countries. The projected increase was found to be sensitive to to the choice of predictors used to model the geographical dependency, rather than to the choice of method.
\end{abstract}

KEY WORDS: Climate scenarios · Empirical-statistical downscaling • Probability density function · $\mathrm{PDF} \cdot$ Extremes

\section{INTRODUCTION}

It is notoriously difficult to determine trends associated with very rare climate extreme events due to the large sampling fluctuations and low number of cases. Nevertheless, precipitation observations suggest an increasing trend in intense precipitation over parts of Europe (Frei \& Schär 2001, Klein Tank \& Können 2003, Hundecha \& Bárdossy 2005, Schmidli \& Frei 2005, Achberger \& Chen 2006) and elsewhere (Frich et al. 2002, Groisman et al. 2005). An analysis of trends over the 1961 to 2004 period by Achberger \& Chen (2006) revealed that there has not been a spatially coherent pattern for Norway and Sweden for the annual 99th percentile, yet the overall aggregated trend was never- theless positive. Alexander et al. (2005) analysed global historical trends and found fewer clear signs of change in the probability density function (PDF) for daily precipitation than for temperature. However, they observed a general tendency towards changes in the precipitation indices consistent with a wetter climate. They documented a lack of large-scale coherent trend patterns for precipitation, but found positive trends for the 1951 to 2003 winter seasonal maximum 5 d precipitation over northern Europe. Furthermore, there was a significant increase in very wet days in general (95th percentile), although the index had an incomplete spatial coverage across the globe. Frich et al. (2002) also analysed the historical evolution of heavy precipitation, and concluded that 'indicators based on daily pre- 
cipitation data show more mixed patterns of change but significant increases have been seen in the extreme amount derived from wet spells and number of heavy rainfall events' (Frich et al. 2002, p. 193).

In addition to analysing the past, a number of studies have addressed how precipitation may change in the future under a global warming scenario. Previous projections based on 19 different global climate model (GCM) simulations with a coarse resolution suggest an increase in the probability of extreme winter precipitation over northern Europe (Palmer \& Räisänen 2002). One caveat is that GCMs provide a representation of mean values for large areas, whereas it is often local extreme rainfall that is of interest. Regional climate models (RCMs) with higher spatial resolution also point to more extreme rainfall amounts over northern Europe as a consequence of a global warming (Christensen \& Christensen 2002); such RCM studies have traditionally only involved a few simulations, yet large model ensembles are usually needed to infer changes in extreme-event statistics. With the completion of the PRUDENCE project (see http://prudence.dmi.dk/) more RCM results have become available from 8 different regional models driven by 4 different GCMs (http://prudence.dmi.dk/public/DDC/extended_table .html). The PRUDENCE results represent a small ensemble in terms of the driving GCMs, mainly based on the HadCM3 model (Frei et al. 2006), which also is reflected in the solutions obtained with the 8 PRUDENCE RCMs. The spatial resolution of the RCMs typically ranges between 10 and $70 \mathrm{~km}$, however, the representation of local extreme precipitation or temperature may not always be adequate as $50 \times 50 \mathrm{~km}^{2}$ averages, as most real observations are made for more local scale precipitation and can be considered as point measurements. Whereas empirically based analyses of the number of rainy days tend to derive the wet-day frequency from actual values, RCMs can be biased (Frei et al. 2006). RCMs nevertheless give useful information about spatial scales up to a few tens of $\mathrm{km}$, and higher-resolution RCMs have been used to improve the fidelity of the projections.

It is possible to define a number of climate extreme indices (Frich et al. 2002, Alexander et al. 2005) and then apply empirical-statistical downscaling (ESD) directly to those. Such work has been carried out within the European Union STARDEX project (www. cru.uea.ac.uk/projects/stardex/). Frich et al. (2002) used an index (R95T) that described the fraction of the total precipitation associated with events exceeding the 95th percentile.

In the present study, 2 new approaches are adopted, both of which involve estimating the change in the parameters describing PDFs representing the statistical distribution of precipitation (P). Downscaling of a
PDF for the variable $X$ given external conditions $Y$ implicitly employs Bayes' theorem (Leroy 1998), i.e. $\operatorname{Pr}(X \mid Y)=[\operatorname{Pr}(Y \mid X) \operatorname{Pr}(X)] / \operatorname{Pr}(Y)$, and is thought to provide a more realistic representation of the upper tails of the distribution than a direct downscaling of the daily values from the climate models (Hayhoe et al. 2004, Pryor et al. 2005, Pryor et al. 2006).

Generalised linear models (GLMs) have not yet been widely used in climate literature (Yan et al. 2006), although there are some publications in climate-research journals authored by people with strong statistics background (Yang et al. 2005, Yan et al. 2006 and references therein). Yang et al. (2005) used GLMs (www.statsoft. com/textbook/stglm.html) to simulate sequences of daily rainfall at a network of sites in southern England, and Yan et al. (2006) used GLMs to simulate sequences of daily maximum wind speeds. One obstacle to the GLM gaining popularity in the wider research community may have been the different cultures of the statistics and physics communities and that the papers on GLMs have been written by statisticians using a rigorous formal statistical treatment that is often difficult to digest for climatologists with physics, meteorology, or geography backgrounds. For GLM-based analysis, a common viewpoint regards each data value as one realisation of a stochastic process, in contrast to the classical Newtonian physics viewpoint where the variable is regarded more as a deterministic response to a set of forcing conditions. Moreover, a GLM approach often assumes that the PDF is varying over time, as opposed to the PDF being constant over time but where each realisation is predicted deterministically, given a set of predictors. Although the differences may seem subtle, the implications are more profound, since the PDF changes from one observation to the next in the former, and it is the PDF that is systematically affected by the forcing (Yan et al. 2006). On the other hand, from a Newtonian viewpoint, systems are regarded as welldefined for which energy, momentum and mass are conserved quantities. Ideally, any state can be determined accurately within the Newtonian framework if all the forcings are known, given these constraints. Unknown factors produce behaviour that is unaccounted for, commonly referred to as 'noise'. If the noise is weak (high signal-to-noise ratio), then the system is practically deterministic, but if the noise is overwhelming, then the system behaves in a stochastic manner. Thus, from a Newtonian viewpoint, the noise is not affected by the known forcing conditions, and the PDF for the response is taken to be independent of that of the noise; whereas in the Bayesian frame, the PDF describing any stochastic behaviour is assumed to be systematically influenced by the external conditions. The implications of stochastic systems are that the principal conditions of causation are not accounted for because different reali- 
sations can be drawn from the same PDF, but there is no way to predict the exact value even if the PDF is well described. In practical terms, however, the 2 approaches are 2 sides of the same problem, but involve completely different interpretations.

Two different and independent approaches are employed in this study, and these will henceforth be referred to as Approach A and Approach B. In the former, the PDFs are modelled through a step-by-step procedure, whereas in the latter, the PDFs are modelled more directly with a GLM. In this study, Approach A is examined and compared with Approach B in the light of validation against independent empirical data. These results will contribute towards an assessment carried out for the Norwegian Agricultural Authority on scenarios for extreme weather events for year 2050.

\section{DATA AND METHODS}

The following convention will be used in this paper: $P$ will denote precipitation amount in general terms, $P_{\mathrm{w}}$ will denote precipitation for wet days, and $P_{\mathrm{a}}$ represents precipitation for all days, and the mean value of $P$ is written as $\bar{P}$. Thus, $\bar{P}_{\mathrm{w}}$ $>\bar{P}_{\mathrm{a}}$ since $P_{\mathrm{a}}$ includes a number of data points with zero value and $P \geq 0 \mathrm{~mm}$ $\mathrm{d}^{-1}$. All seasons were included in the estimations of the PDFs and the mean climatic conditions ( $\bar{T}$ and $\bar{P}_{\text {ai }}$ where $\bar{T}$ is the mean value of temperature). The PDFs in this study represent the local (single station) precipitation rather than areal means, and all seasons rather than a particular time of year.

Daily precipitation amounts were obtained from the European Climate Assessment, ECA, (Klein Tank et al. 2002) as well as the data archive of the Norwegian Meteorological Institute (NMI). The station series do not all start at the same date, as the start dates of the series depend on the availability of the data (when routine observations were established and from which dates the data have been digitised). The observations used in the daily NMI records started between 1950 and 1982 depending on the station, whereas the daily ECA data start between 1900 and 1979. Most of these series contain data up to 2005. The ECA data has not been homogenised (Wijngaard et al. 2003), and neither has the NMI data. A total of 49 stations was used in the analysis of 49 different PDFs representing various locations that span the latitude range from Greece and Spain in southern Europe to Svalbard in the Arctic (circles in Fig. 1; list of 'Dependent' stations in Appendix 1); 'daily data' henceforth refer specifically to data from these stations.

ESD has been used to estimate the local mean climatic conditions (Benestad 2005). Since the downscaled changes in the mean conditions have been thoroughly documented in Benestad (2005), we will not dwell with the ESD technicalities here other than providing a short description; however, more details are given in Appendix 2.

The set of station data used for the ESD analysis in Benestad (2005) differ from the selection of stations used to examine the daily precipitation distributions, with monthly instead of daily data. The former consisted of 102 independent local series of temperature and 119 independent local series of precipitation (henceforth referred to as 'monthly data'). The monthly data were used for inferring changes in the mean temperature $(\bar{T})$ and precipitation $\left(\bar{P}_{\mathrm{a}}\right)$. The monthly data station locations are indicated by triangles and squares in Fig. 1 and the stations are listed in Appendix 3.

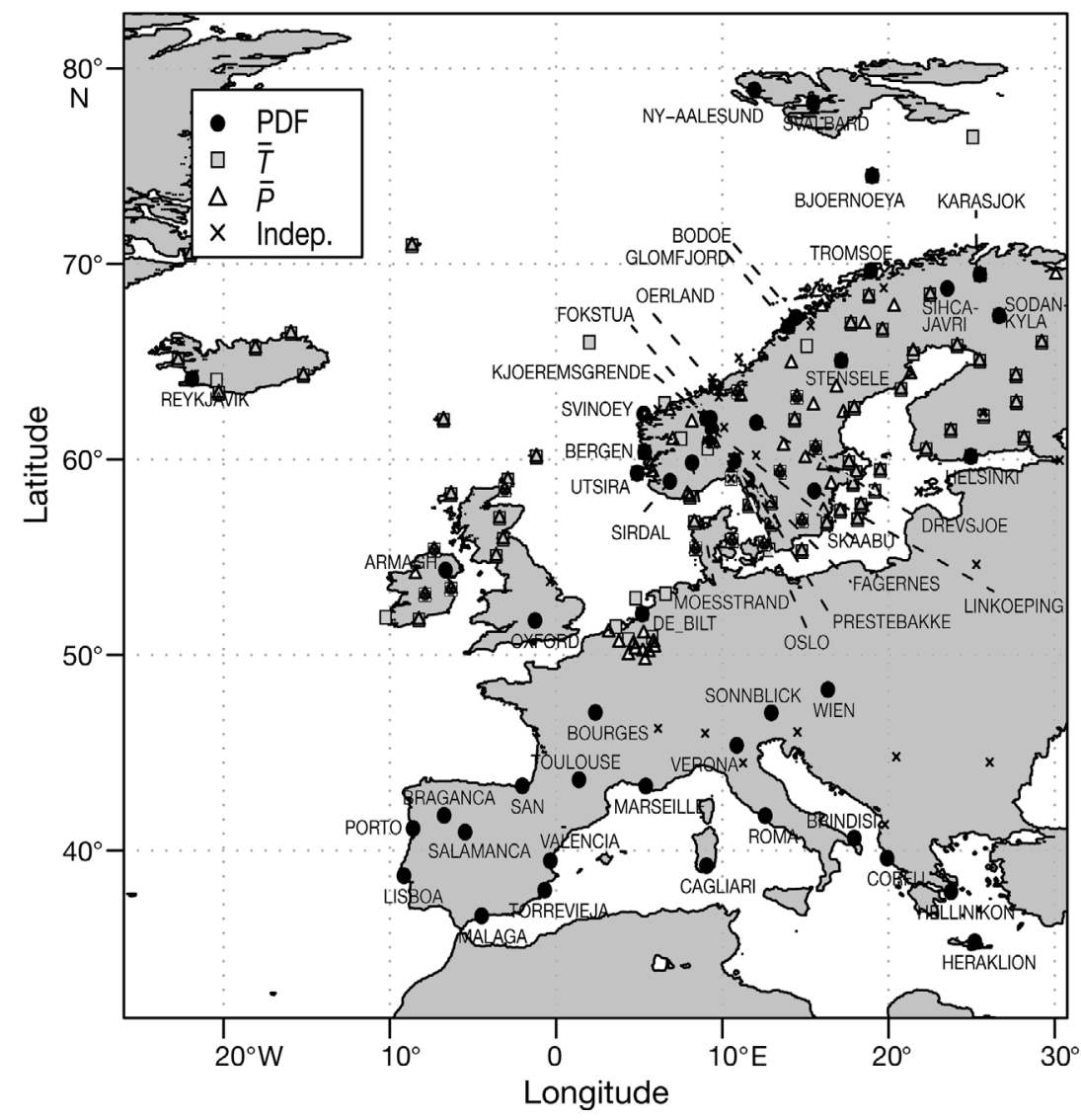

Fig. 1. Location of the (daily) station series used for estimating the linear exponential law slope $m(\bullet)$ in the present study, as well as stations used for mapping the mean (monthly) temperature $\left(\bar{T}_{;} \square\right)$ and precipitation $\left(\bar{P}_{;} \Delta\right)$ in Benestad (2005). Indep.: independent local precipitation series 
The number of stations and locations were determined by the data availability and quality. Most of the stations with daily data are located in northern Europe as this was the focus area of this study. Only wet days with precipitation exceeding a threshold value of $1 \mathrm{~mm} \mathrm{~d}^{-1}$ were used for constructing the histograms and fitting PDFs because of uncertainties associated with low values (false readings associated with condensation or fog).

Scenarios for PDFs representing 2050 have been inferred indirectly through ESD (Benestad 2005), where trends from transient runs were used to estimate the future conditions: $\bar{T}^{*}=\bar{T}+\Delta T$ and $\bar{P}_{\mathrm{a}}{ }^{*}=\bar{P}_{\mathrm{a}}$ $+\Delta P_{\mathrm{a}}$. Here, the asterisk $X^{*}$ is used to signify the scenario for 2050 . The changes $\Delta X$ were estimated from the linear annual mean trends according to $\Delta X$ $=\mathrm{d} X / \mathrm{d} t \times \Delta t$, and $\Delta t$ was taken to be 50 yr. The climate scenarios were taken from the most recent GCM simulations carried out for IPCC AR4, and the results presented here represent the IPCC SRES A1b emission line.

When histograms for daily precipitation are plotted with a log-scale along the vertical axis, a close to linear dependency to magnitude is evident (see Fig. 2). The following definitions are used: let $y\left(P_{\mathrm{w}}\right)=\ln \left|\hat{n}_{\mathrm{P}}\right|$, where $\hat{n}_{\mathrm{P}}$ is the number of $P_{\mathrm{w}}$ events with values falling within the interval $P_{\mathrm{w}}$ and $P_{\mathrm{w}}+\delta P_{\mathrm{w}}\left(\delta P_{\mathrm{w}}\right.$ was taken to be $2 \mathrm{~mm}$ ). The linear model $\hat{y}=m^{\prime} P_{\mathrm{w}}+C^{\prime}$ is then used to represent the linear dependency between counts and magnitude, and a weighted leastsquares regression was used to solve for $\mathrm{m}^{\prime}$ and $C^{\prime}$, taking $P_{\mathrm{w}}$ as the predictor and the log of the counts as the predictand (the weights were taken as $\sqrt{n_{\mathrm{P}}}$ in order to emphasise the cases with a greater statistical sample). The convention used here is that $m^{\prime}$ and $\hat{m}$ are different estimates of the $m$ based on different models and used in different situations. A linear dependency $\ln \left|n_{P}\right| \propto P_{\mathrm{w}}$ implies a simple exponential distribution, $n_{P} \propto \mathrm{e}^{m P_{\mathrm{W}}}$ with $m<0$, and has one advantage that the PDF can be written as $f\left(P_{\mathrm{w}}\right)=$ $-m \mathrm{e}^{m P_{\mathrm{w}}}$ because the area under the PDF curve must equal unity (the expression is derived in Appendix 4, Eq. A1). Another useful property is that the mean $\mu$ and any percentile $q_{p}$ for the wet-day distribution can easily be derived analytically (see Appendix 5, Eq. A2) given the exponential coefficient $m$ :

$$
\begin{aligned}
& \mu^{+}=-1 / m \\
& q_{p}^{+}=\ln (1-p) / m
\end{aligned}
$$

Here, $\mu^{+}$and $q_{p}^{+}$represent the analytical solutions for Eq. (1), and $p$ is the probability level, not to be confused with $P$ which is the precipitation amount.

Both changes in the number of rainy days per year $N_{\mathrm{R}}$ and changes in the PDF must be known in order to infer changes in probability of rainfall amounts exceeding a given threshold value. The probability for rainfall amount exceeding any given wet or dry present-day percentile can be estimated from Bayes' theorem:

$$
\operatorname{Pr}\left(P>q_{p} \mid \text { wet }\right)=\frac{\operatorname{Pr}\left(\text { wet } \mid P>q_{p}\right) \operatorname{Pr}\left(P>q_{p}\right)}{\operatorname{Pr}(\text { wet })}
$$

By rearranging Eq. (2) and using the fact that $\operatorname{Pr}\left(\right.$ wet $\left.\mid P>q_{p}\right)=1$ (it is always wet when the rainfall exceeds $q_{p}>0$ ), the probability of the precipitation exceeding the threshold level for any day is given by the product between the cumulative distribution function (CDF) for $P_{\mathrm{w}}$ and the fraction of wet days:

$$
\begin{aligned}
\operatorname{Pr}(\text { wet }) & \times \operatorname{Pr}\left(P>q_{p} \mid \text { wet }\right) \\
& =\frac{N_{\mathrm{R}}}{365.25} \times\left(1-\int_{0}^{q_{p}}-m \mathrm{e}^{m P} \mathrm{~d} P\right)=\frac{N_{\mathrm{R}} \mathrm{e}^{m q_{p}}}{365.25}
\end{aligned}
$$

Here, $\operatorname{Pr}$ (wet) is just the fraction of rainy days to total number of days in the year, and an analytical solution is easily found for the integral: $\int_{\mathrm{x}_{1}}^{x_{2}} \mathrm{e}^{m x} \mathrm{dx}=\left[\mathrm{e}^{m x} / m\right]_{\mathrm{x}_{1}}^{x_{2}}=$ $\left(\mathrm{e}^{m x_{2}}-\mathrm{e}^{m x_{1}}\right) / m$.

Geographical models were used for the production of maps for $m, N_{\mathrm{R}}$, percentiles and probabilities, based on multiple regressions similar to those employed in Benestad (2004c) and Benestad (2005). Initially, the mean temperature $(\bar{T})$, precipitation $\left(\bar{P}_{\mathrm{a}}\right)$, logarithm of the altitude $(\ln [z])$, square root of the distance to the coast $(\sqrt{d})$, eastings $(x)$, and northings $(y)$ were used as predictors, and a stepwise screening based on the Akaike information criterion, AIC (Wilks 1995, p. 301-302) was used to exclude the variables without predictive skill.

\subsection{Approach A}

For Approach A, the multiple regression analysis identified the empirical relationship between $m$ on the one hand and the local $\bar{T}\left({ }^{\circ} \mathrm{C}\right)$ and $\bar{P}_{\mathrm{a}}\left(\mathrm{mm} \mathrm{d}^{-1}\right)$ on the other:

$$
\begin{aligned}
\hat{m}= & -(0.233 \pm 0.009)+(0.006 \pm 0.001) \bar{T} \\
& +(0.019 \pm 0.004) \bar{P}_{\mathrm{a}}
\end{aligned}
$$

A step-wise multiple regression analysis that also included the quadratic terms $\bar{T}^{2}$ and $\bar{P}_{\mathrm{a}}^{2}$ in the initial set of predictors gave:

$$
\begin{aligned}
\hat{m}= & -(0.247 \pm 0.012)+(2.7 \pm 1.5) \times 10^{-3} \bar{T} \\
& +(0.024 \pm 0.004) \bar{P}_{\mathrm{a}}+(3.1 \pm 0.1) \times 10^{-4} \bar{T}^{2} \\
& +(1.7 \pm 0.9) \times 10^{-3} \sqrt{d}-(2.3 \pm 1.1) \times 10^{-5} X
\end{aligned}
$$

where $d$ is the distance from the coast $(\mathrm{km})$ and $x$ represents eastings ( $\mathrm{km}$ from $10^{\circ} \mathrm{E}$ meridian). (See Tables 1 $\& 2$ for further details about the regression analysis). The analysis is based on all the stations, and reflects the geographical variations in $m$. 


\subsection{Approach B}

A maximum likelihood estimation (MLE) is used to derive a model for the expectation value $E(\cdot)$ for a variable $Y_{t}$ at any given time $t: E\left(Y_{t}\right)=\mu_{t}=g^{-1}(X \beta)$. Here, $\mu_{t}$ is the mean for the PDF $\left[\mu_{t}=\int_{-\infty}^{\infty} y f_{\mathrm{t}}(y) \mathrm{d} y\right]$ at time $t$, rather than the empirical average for the entire sequence $(\bar{Y})$, and $g(\cdot)$ is a function that determines the scale on which the predictors are additive. The variance function used by the GLM was $V(\mu)=\mu$ (assuming a Poisson process). Note that in Approach B, the GLM predicts the mean $\mu$ of the distribution rather than the realisation itself. Thus, Approach B employed a generalised linear model (GLM) to predict $\mu$ directly:

$$
\ln (\mu)=\beta_{0}+\beta_{1} \bar{T}+\beta_{2} \bar{P}_{\mathrm{a}}+\beta_{3} \bar{T}^{2}+\beta_{4} x+\beta_{5} \ln (z)
$$

This exercise was also repeated with $\mu$ replaced by $q_{p}$ for the prediction of percentiles $\left(\hat{q}_{\mathrm{p}}\right)$ in a more traditional fashion. The regression analysis just by itself, however, does not provide a description of the PDF the same way as Approach A does, but if the estimates of $\mu$ are used in connection with Eq. (1), then it is possible to use GLM to estimate PDFs too. This approach is similar to that of Yan et al. (2006), who assumed either Gamma or Weibull distributions and constant shape parameters, and then used $\mu$ to infer the PDF for given time. Thus Approaches A and $\mathrm{B}$ are methodologically independent. In order to assess the skill of the analysis, empirical values obtained with the analytical expressions $\mu=-1 / m^{\prime}$ (Eq. 1) were compared with the GLM predictions. It should be noted here that $\mu$ is not independent of $\bar{P}$ in Approach B, as both contain the same data for rainy days.

\subsection{Number of wet days}

A stepwise multiple regression analysis was used to examine the relationship between $N_{\mathrm{R}}$ and local $\bar{T}, \bar{P}_{\mathrm{a}}$ as well as the other geographical parameters, yielding the following equation:

$\ln \left(\hat{N}_{\mathrm{R}}\right)=4.88 \pm 0.23+(0.22 \pm 0.05) \bar{P}_{\mathrm{a}}-(0.048 \pm 0.008) \bar{T}$ $-(0.05 \pm 0.03) \ln (z)+(1.9 \pm 1.0) \times 10^{-4} X-(2.9 \pm 0.9) \times 10^{-4} y$

Here, only stations with $N_{\mathrm{R}}>30 \mathrm{~d}$ were included in the calibration of Eq. (7), and the predictors have the same units as in Eqs. (4) to (6). The regression analysis assumed a Poisson distribution for the counts, and hence used a GLM with a $\log$-link: $g(\cdot)=\ln (\cdot)$; however, the results were not critically sensitive to this choice.

\subsection{Result mapping}

The mapping of $m$ and $N_{\mathrm{R}}$ required high-resolution gridded values of both $\bar{T}$ and $\bar{P}_{\mathrm{a}}$. Maps of $\bar{T}$ and $\bar{P}_{\mathrm{a}}$ had been constructed though a similar geographical information system (GIS) type analysis (Benestad 2005), involving a multiple regression between $\bar{T}$ or $\bar{P}_{\mathrm{a}}$ and the respective station coordinates, north-south/east-west slopes, altitude, and distance from the coast, employing a stepwise screening. The residuals from the multiple regression analysis, based on Eqs. (4) to (7), were added to the predictions by employing spatial interpolation (see Appendix 6). For the maps presented here, stations with dry southern European climates $N_{\mathrm{R}}<30 \mathrm{~d}$ were excluded in the regression analyses, implying that Eqs. (4) \& (5) were calibrated with a subset of the data originally used for their calibration.

\section{RESULTS}

The least-squares fits to the exponential slopes are shown as black dashed lines for each location in Fig. 2. Also marked in the panels are the mean and 95th percentiles for each location. A linear fit is only used as an approximate description here, as a gamma fit may often yield a more accurate representation of the upper tails of the precipitation distribution. It can be shown that the exponential law is not very different to the more commonly used gamma distribution when its parameters are fitted to provide a best-fit to the daily precipitation amounts. The gamma parameter's shape and scale also show a highly statistically significant relationship with local climatic conditions (Benestad et al. 2005). A linear exponential distribution provides simpler analytical solutions, and reduces the number of unknown parameters to fit. Furthermore, the upper tails involve a smaller number of events and are thus affected by uncertainty associated with statistical fluctuations (also due to intraseasonal, inter-annual, and decadal variability) to a higher degree than less extreme values.

The exponential slope $m^{\prime}$ for the linear fit to the logarithm of the counts (the exponential coefficient) varies from site to site, but a multiple regression analysis against the local mean temperature, precipitation, eastings and northings (Eqs. 4 \& 5) suggests that the rainfall distribution depends on such local conditions, as the $p$-value of the stepwise multiple regression based on a linear combination of local climatic variables is $3.0 \times 10^{-14}$ and the adjusted $\mathrm{R}^{2}$ is 0.73 (Table 1 ). However, the step-wise screening is not robust, because when the squared mean temperature and precipitation are added to the set of predictors before step-wise screening, then eastings, the square root of the altitude $\sqrt{z}$, and $\bar{T}^{2}$ also pass the step-wise screening test as a skillful predictors, and Eq. (5) yields a $\mathrm{p}$-value of $2.4 \times 10^{-14}$ and an adjusted $\mathrm{R}^{2}=0.79$ (Table 2 ).

It is important to validate Eqs. (4) \& (5), and Fig. 3a shows a comparison between estimates of $m^{\prime}$ accord- 


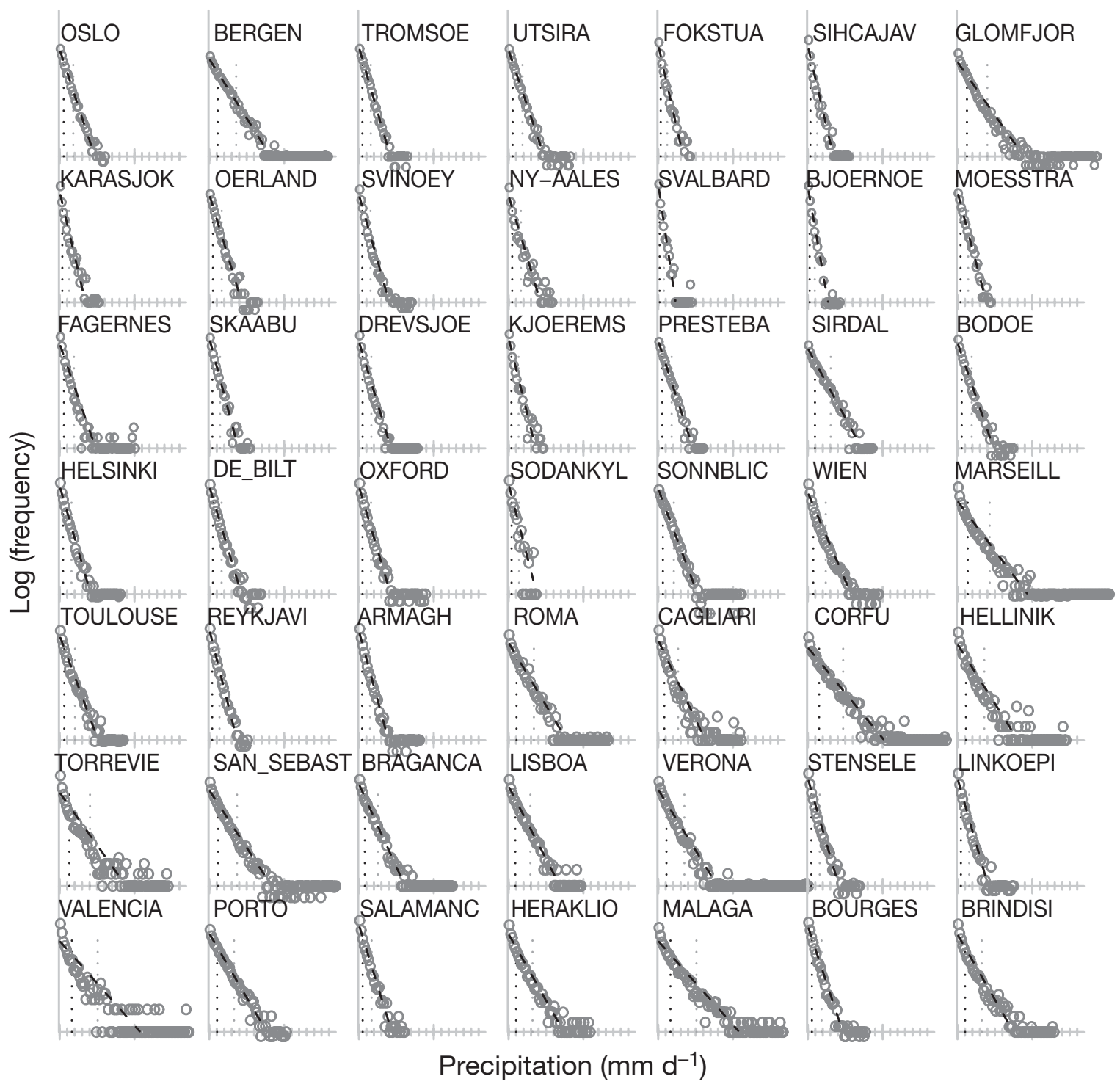

Fig. 2. Linear best-fits (- - ) of $\hat{y}=\mathrm{e}^{a+b_{x}}$ to the log-linear distribution $(\bigcirc)$ of $24 \mathrm{~h}$ precipitation. For each plot the $y$-axis shows the log of the frequency (dimensionless, as the no. of wet days varies between stations) and the $x$-axis the linear scale of precipitation amounts (each tick $=10 \mathrm{~mm} \mathrm{~d}^{-1}$ ). Vertical dotted lines: theoretical estimates for the mean $\mu^{+}$(dark grey) and 95th percentile $q_{0.95}{ }^{+}$(light grey). Low precipitation cut-off: $1 \mathrm{~mm}$

ing to Eq. (5) (derived from slope analysis based on an ordinary linear regression analysis shown as dashed black lines in Fig. 2) on the $x$-axis and predicted values $(\hat{m})$ on the $y$-axis. The results from Eq. (4) were similar

Table 1. Ordinary linear regression model for $\hat{m}$ with linear terms: Residual SE: 0.032 on 46 df. Multiple $\mathrm{R}^{2}: 0.74$; adjusted $\mathrm{R}^{2}$ : 0.73. F-statistic: 66.11 on 2 and $46 \mathrm{df}_{\text {; }} \mathrm{p}$ : $2.96 \times 10^{-14}$. $\mathrm{p}<0.001$ for all values

\begin{tabular}{|lcccc|}
\hline & Estimate & SE & $t$-value & $\operatorname{Pr}(>|t|)$ \\
\hline Intercept & -0.23 & $9.51 \times 10^{-3}$ & -24.464 & $<2 \times 10^{-16}$ \\
$\bar{T}$ & $6.25 \times 10^{-3}$ & $6.45 \times 10^{-4}$ & 9.69 & $1.11 \times 10^{-12}$ \\
$\bar{P}_{\mathrm{a}}$ & $1.92 \times 10^{-2}$ & $3.71 \times 10^{-3}$ & 5.18 & $4.86 \times 10^{-6}$ \\
\hline
\end{tabular}

and are therefore not shown. Grey symbols for the 49 stations used to calibrate Eq. (5), and black symbols for the independent data are also shown. Lists of the locations used for calibrations and locations used for the independent validations not used for tuning the equation are given in Appendix 1. The scatter plot (Fig. 3a) suggests that the points tend to lie along the diagonal. A similar exercise with respect to Eq. (7) also indicates that the number of rainy days $N_{\mathrm{R}}$ (for $N_{\mathrm{R}}>30$ ) to a large degree can be predicted from the mean precipitation, temperature, and location (Fig. 3b). The results and the skill of the regression for $N_{\mathrm{R}}$ are provided in Table 3. An inspection of the results for the different predictors suggests that the $\bar{P}_{\mathrm{a}}$ and $\bar{T}$ were statistically 

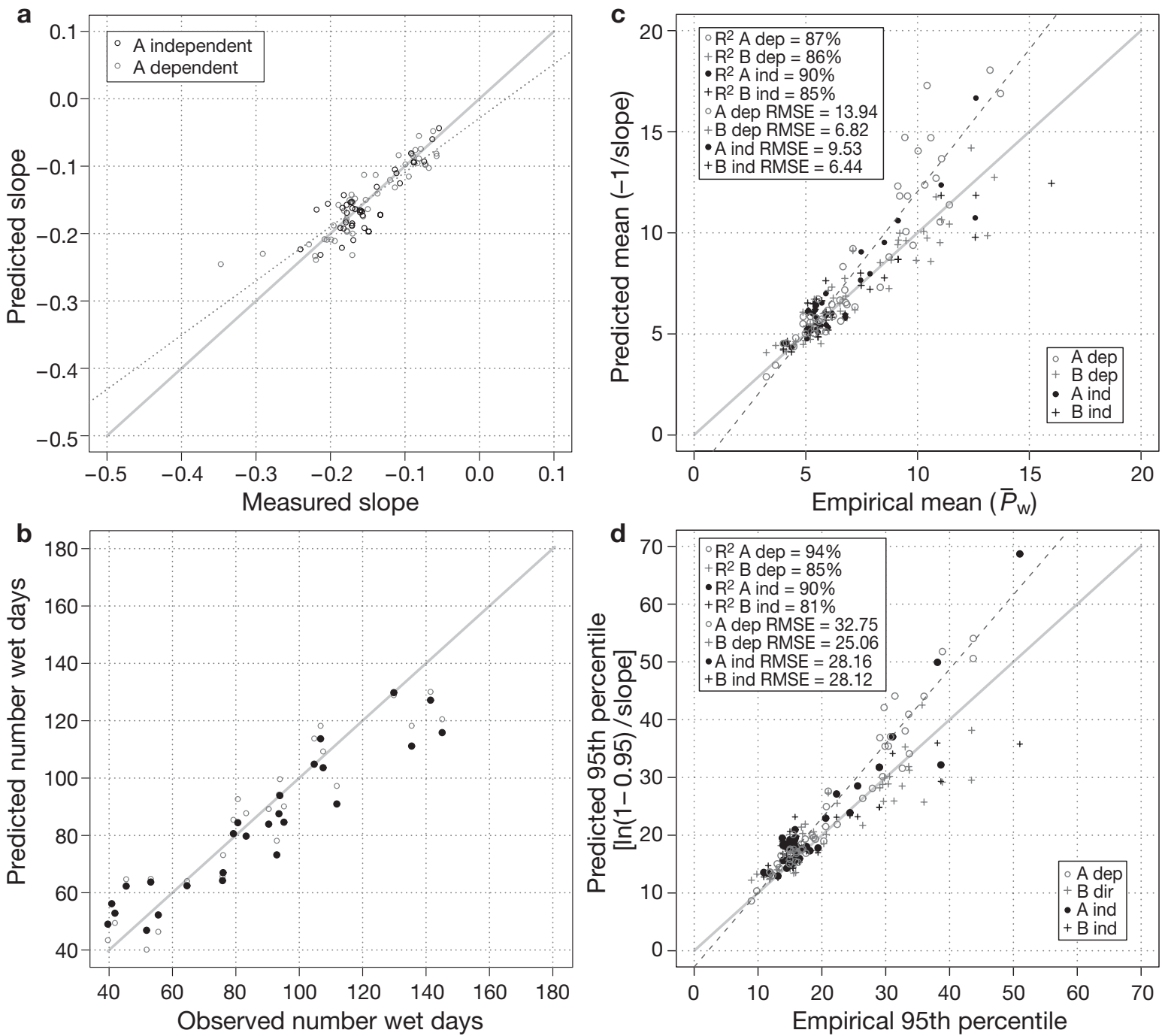

Fig. 3. Validation of statistical models. (a) Slopes estimated from best-fit slopes in Fig. 2 against slopes predicted according to Eq. (5); ( $\left(\right.$ ) dependent data, (O) independent data (see Appendix 1). (b) Observed and predicted $N_{\mathrm{R}}$ based on Eq. (7); (•) GLM with log-link, $(\circ)$ ordinary linear regression. (c) Comparison between mean (derived assuming $\mu^{+}=-1 / \mathrm{m}$ ), and actual mean of the wet-day precipitation, $\bar{P}_{\mathrm{w}}$ for Approach A for $(\odot)$ dependent, and $(\bullet)$ independent data; as well as validation of Approach B for both dependent (grey ' + '), and independent data (black ' + '). (d) Comparison between modelled $\mathrm{q}_{\mathrm{p}}^{+}$and empirical values for the $95 \%$ percentiles (for rainy days only). Results from Approaches A and B are shown for both (light grey symbols) dependent, and (dark symbols) independent data. Solid grey line: slope of perfect model; dashed line: predicted slope from the scatterplot. The weak scatter about the diagonal indicates good correspondence between predictions and empirical data. The $\mathrm{R}^{2}$ score is taken as the square of the correlation coefficient between empirical and predicted values. For panels (c) and (d) low precipitation cut-off $=1$

Table 2. Ordinary linear regression model for $\hat{m}$ with quadratic terms: Residual SE: $2.86 \times 10^{-2}$ on 43 df. Multiple $\mathrm{R}^{2}$ : 0.81 ; adjusted $\mathrm{R}^{2}$ : 0.79. F-statistic: 36.13 on 5 and $43 \mathrm{df} ; \mathrm{p}=$ $2.421 \times 10^{-14} \cdot{ }^{* * *} \mathrm{p}<0.001 ;{ }^{* *} \mathrm{p}<0.01 ;{ }^{*} \mathrm{p}<0.05$

\begin{tabular}{|lccccc|}
\hline & Estimate & SE & $t$-value & $\operatorname{Pr}(>|t|)$ & $\mathrm{p}$ \\
\hline Intercept & -0.25 & $1.23 \times 10^{-2}$ & -20.18 & $<2 \times 10^{-16}$ & $* * *$ \\
$\bar{T}$ & $2.73 \times 10^{-3}$ & $1.45 \times 10^{-3}$ & 1.88 & $6.64 \times 10^{-2}$ & $\cdot$ \\
$\bar{P}_{\mathrm{a}}$ & $2.38 \times 10^{-2}$ & $3.62 \times 10^{-3}$ & 6.58 & $5.27 \times 10^{-8}$ & $* * *$ \\
$\bar{T}^{2}$ & $3.13 \times 10^{-4}$ & $9.24 \times 10^{-5}$ & 3.39 & $1.52 \times 10^{-3}$ & ${ }^{* *}$ \\
$\sqrt{d}$ & $1.70 \times 10^{-13}$ & $9.12 \times 10^{-4}$ & 1.86 & $6.95 \times 10^{-2}$ & $\cdot \mathrm{p}<0.1$ \\
$x$ & $-2.33 \times 10^{-5}$ & $1.06 \times 10^{-5}$ & -2.21 & $3.28 \times 10^{-2}$ & $*$ \\
\hline
\end{tabular}

Table 3. General linear regression model for $\ln \left(N_{\mathrm{R}}\right)$. Null deviance: 4.53 on $26 \mathrm{df}_{\text {; }}$ residual deviance: 0.79 on $21 \mathrm{df}$. AIC: -4.73 . p: as in Table 2

\begin{tabular}{|lccrcc|}
\hline & Estimate & SE & $t$-value & $\operatorname{Pr}(>|t|)$ & $\mathrm{p}$ \\
\hline Intercept & 4.88 & 0.23 & 21.45 & $9.20 \times 10^{-16}$ & ${ }^{* * *}$ \\
$\bar{T}$ & $-4.76 \times 10^{-2}$ & $7.75 \times 10^{-3}$ & -6.15 & $4.26 \times 10^{-6}$ & ${ }^{* * *}$ \\
$\bar{P}_{\mathrm{a}}$ & 0.22 & $5.27 \times 10^{-2}$ & 4.15 & $4.53 \times 10^{-4}$ & $* * *$ \\
$\ln (z)$ & $-5.10 \times 10^{-2}$ & $2.54 \times 10^{-2}$ & -2.00 & $5.84 \times 10^{-2}$ & $\cdot$ \\
$x$ & $1.74 \times 10^{-4}$ & $9.71 \times 10^{-5}$ & 1.79 & $8.77 \times 10^{-2}$ &. \\
$y$ & $-2.93 \times 10^{-4}$ & $9.80 \times 10^{-5}$ & -2.99 & $6.95 \times 10^{-3}$ & $* *$ \\
\hline
\end{tabular}


significant at the $0.1 \%$ level. The strong association between the number of rainy days, $N_{R}$, and the mean precipitation, $\bar{P}_{\mathrm{a}}$, can be explained by more rainy days contributing to the average, since the average derived from the PDF for wet day precipitation amount is $\bar{P}_{\mathrm{w}}=$ $\mu=\int_{0}^{\infty}-m x \mathrm{e}^{m x} \mathrm{~d} x=-1 / m$ when $m<0$, and $\bar{P}_{\mathrm{a}} \approx N_{\mathrm{R}} /$ $365.25 \times 1 /(-m)$ (this is an under-estimate due to the cut-off at $1 \mathrm{~mm} \mathrm{~d}^{-1}$; see Appendix 4, Eq. A1 for derivation of this expression). The negative relationship between $N_{\mathrm{R}}$ and the mean temperature, $\bar{T}$, in Eq. (7) can be explained by the fact that there are more rainy days in the north with colder climates.

The root mean square error (RMSE) for $\hat{m}$ is 0.029 and $13.43 \mathrm{~d} \mathrm{yr}^{-1}$ for $\hat{N}_{\mathrm{R}}$. Whereas plots of errors versus the value did not show clear signs of heteroscedastic behaviour in $m$ (the errors are drawn from different distributions for different values of the independent variables), there was a tendency that the largest errors in $N_{\mathrm{R}}$ were associated with those locations characterised by larger fractions of rainy days (not shown).

Fig. 3c,d shows comparisons between estimates obtained using Eq. (1) and corresponding mean and percentiles obtained empirically from the measurements. The scatter-plots show results from both Approach A and Approach B. Both dependent data, on which the statistical models were calibrated, and independent data are shown (see Fig. 1, Appendix 1). In general, there is a good agreement between $\mu^{+}$and $\bar{P}_{\mathrm{w}}$ and between $q_{0.95}^{+}$and empirical estimates of $q_{0.95}$. Thus, a simple exponential distribution implies that the probability for extreme values can be inferred simply from knowing the value of $m$ or $\mu$, given a rainy day. Also shown in the scatter plots are the values predicted directly using GLM and Eq. (6). The skill of the methods are compared in terms of the degree of scatter: $\mathrm{R}^{2}=\operatorname{cor}\left(\bar{P}_{\mathrm{w}}, \mu^{+}\right)^{2}$, and the magnitude of bias expressed in terms of root mean square error: RMSE $=\sqrt{\Sigma\left(\bar{P}_{\mathrm{w}}-\mu^{+}\right)^{2}}$. The 2 different approaches yield similar results for both dependent and independent data, albeit the direct GLM modelling of $\mu$ and $q_{0.95}$ gives a negative bias for the larger values, whereas Approach A produces a positive bias. The biases are generally greater for Approach A than Approach B, but they are comparable for the independent data and the 95th percentile. On the other hand, the results derived through Approach A have a stronger correlation with the empirical data than do those of Approach B.

Fig. $3 \mathrm{~d}$ suggests that the theoretical values $q_{p}^{+}$tend to over-estimate the percentiles (lying above the diagonal), especially towards the higher values. Such overestimation could suggest that the theoretical framework yields an upper tail biased to higher values, but the empirical distributions in Fig. 2 suggest more observed extreme events (clutter of grey circles in the upper tail of the distributions) than are predicted by the theoretical analysis (black dashed lines). However, $q_{0.95}$ is shown as vertical dotted grey lines for each location in Fig. 2, and the impression that Eq. (1) under-estimates the number of cases is caused by the most extreme percentiles far out in the tail, rather than the more 'moderate' $q_{0.95}$.

Present analysis has neglected the cases where $0<P<$ $1 \mathrm{~mm} \mathrm{~d}^{-1}$ with the justification that the relative errors amount to a large fraction of the small amounts. There is a risk that the inclusion of the data with $0<P<1 \mathrm{~mm} \mathrm{~d}^{-1}$ may lead to different distribution, but repeating the analysis of Fig. 2 for $P>0 \mathrm{~mm} \mathrm{~d}^{-1}$ did not change the picture (not shown). The proportion of the rainfall with $0<$ $P<1 \mathrm{~mm} \mathrm{~d}^{-1}$ represents $<10 \%$ of the total amount for most of the locations, and $<20 \%$ of the days.

Fig. 4 a shows a map of $q_{0.95}^{+}$for the present-day conditions. The projections for future changes in the wet-day 95th percentile, given changes in the mean precipitation and temperature, were obtained by replacing $\bar{T}$ and $\bar{P}_{\text {a }}$ with $\bar{T}+\Delta T$ and $\bar{P}_{\mathrm{a}}+\Delta P_{\mathrm{a}}$, respectively, in Eqs. (4) \& (5) (Fig. 4b). The projected increase in the 95th percentile for the year 2050 is estimated to be -6 to $\pm 10 \%$ for most of the region studied, with negative values over mountainous regions and little change in the Arctic (Fig. 4b). The most pronounced changes can be seen in the south and along the western coasts of Norway and Sweden, as well as over the British Isles, Denmark, northern Germany and the Netherlands. Assuming that the statistical association between the number of rainy days per year and the mean level of precipitation and temperatures hold in the future, then the estimates of $N_{R}$ for 2050 suggest an increase (up to 10 to $20 \mathrm{~d} \mathrm{yr}^{-1}$ ) in the average number of rainy days (Fig. 4c).

Fig. $4 \mathrm{~d}$ shows projected changes in the probability of extreme precipitation, here defined as the amount exceeding present-day $q_{0.95}$ for all days (dry + wet). The results shown are the ratio of the 2 solutions of Eq. (3) with values of $m$ and $N_{R}$ representing the present day and the year 2050 respectively: $\operatorname{Pr}\left(X^{*}>\right.$ $\left.q_{0.95}^{+}\right) / \operatorname{Pr}\left(X>q^{+}{ }_{0.95}\right)$. Thus, these results suggest that the probability for exceeding the present 95th percentile may increase by up to $30 \%$ in relative terms.

Fig. 4e maps the difference in probability for $24 \mathrm{~h}$ precipitation exceeding the present-day $q_{0.95}$ based on the indirect GLM results from Approach B, showing similar results as those derived using Approach $A$, albeit with weaker spatial variance and in general a more modest change. Fig. 4f shows a corresponding analysis to the map presented in Fig. $4 d$, but where only the linear terms in temperature and precipitation (Eq. 4) were considered as opposed, including the quadratic terms (Eq. 5). The results based on the linear variables indicate a shift to more frequent events exceeding the present-day $q_{0.95}$ everywhere, but with a more pronounced increase at higher altitudes as 

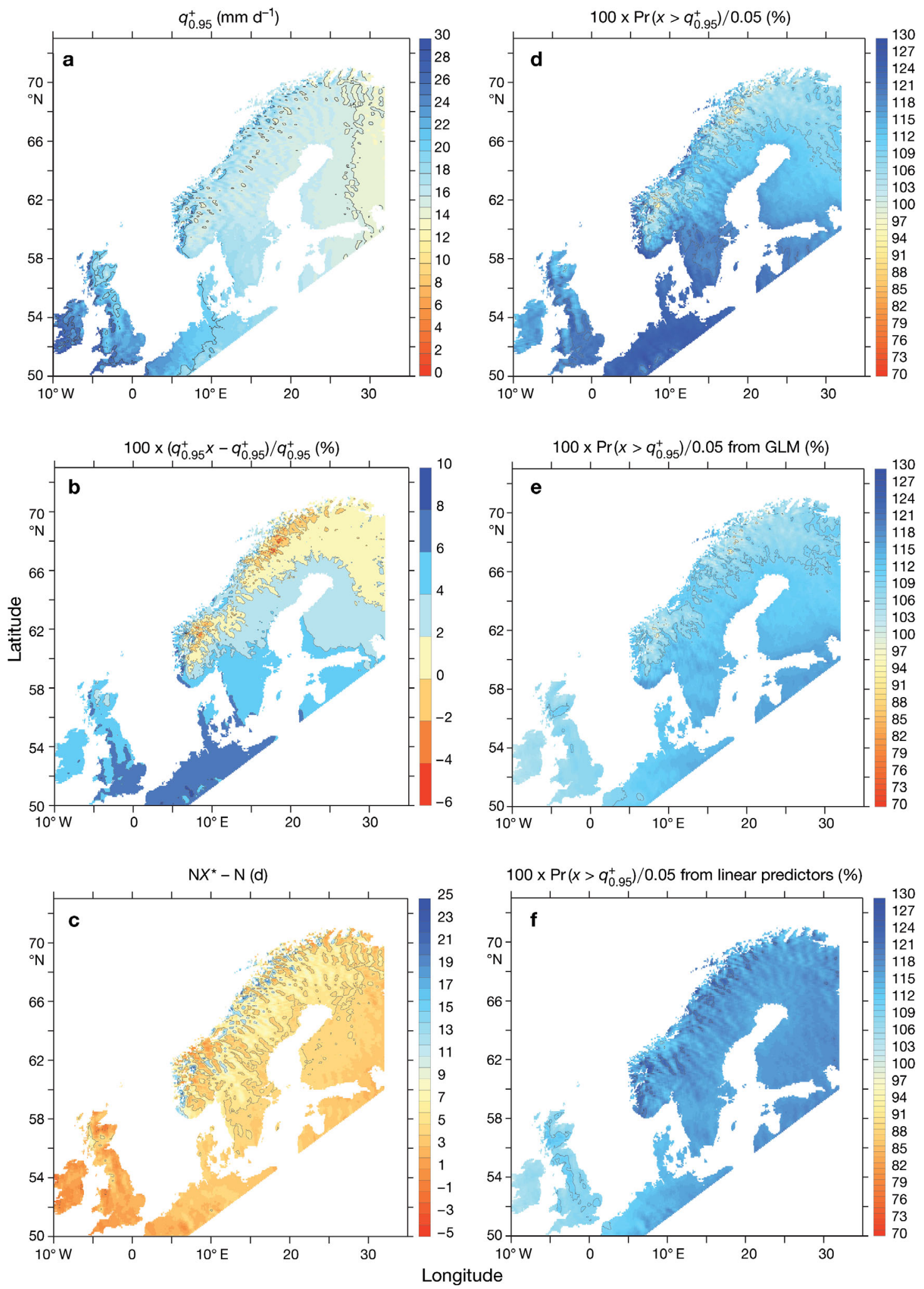

Fig. 4. (a) Estimates of $q_{0.95}^{+}$for the present-day conditions based on ECA and data from the Norwegian Meteorological Institute. The values have been gridded using a GIS-type approach. (b) Relative change in $q_{0.95}^{+}$projected for 2050 assuming the SRES A1b emission scenario. (c) Estimated change in the mean number of rainy days per year $\left(\mathrm{p}>1 \mathrm{~mm} \mathrm{~d}^{-1}\right)$. (d,e,f) The probability ratio $\operatorname{Pr}\left(X^{*}>q_{0.95}^{+}\right) / \operatorname{Pr}\left(X>q_{0.95}^{+}\right)$for rainfall amount exceeding present-day $q_{0.95}^{+}$for any given day based on different methods and geographical models 
opposed to a diminishing change with height. Thus, the choice of predictors included in the step-wise screening has a greater effect on the end results than the choice of approach, even when both cases yield strong statistical relationships (Tables 1 \& 2).

\section{DISCUSSION}

The projection based on Eqs. (5) \& (7), empiricalstatistical downscaling, and the sub-grid parameterisation schemes in the GCMs all assume that the established relationship between the predictors and predictands is valid for the future. There are also uncertainties associated with cascading errors terms involving: (1) emission scenarios; (2) GCM misrepresentations; (3) shortcomings associated with ESD including both observation errors and statistical modelling errors; (4) approximations associated with the exponential-law type PDF; and (5) errors associated with the statistical model for the relationship between slope $m$ and climatic and geographic parameters. The 2 different approaches produce different biases, but both nevertheless produce similar and skilful predictions for the 95th percentile. An over-estimation of $q_{0.95}$ (Fig. 3c) may result in a bias of the estimated changes in the upper percentiles, but this bias may not be systematic for all percentiles as the observed extremes at the very upper range of the distributions appear to occur more frequently than the predictions by Eq. (5). A bias in $q_{p}^{+}$affects the limits used in the estimation of the probability (Eq. 3), and an over-estimate in $q_{p}$ will result in an under-estimation of the probabilities $(m<0$

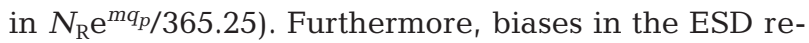
sults may affect the prediction of the PDFs for the future scenarios, and it is therefore important to assess the realism and errors of these.

Non-constant PDFs render the analysis of returnintervals and return-values from extreme value modelling results hard to interpret (Benestad 2004b). Here, PDFs are inferred in a Bayesian fashion from mean conditions for the year 2050 (Fig. 4b) rather than for an interval over which the quantity changes. The precipitation data used for calibrating the relationship between the PDF parameters $(m)$ and the local mean climatic conditions is believed to be close to being independent and identically distributed (iid), as previous analysis for maximum monthly $24 \mathrm{~h}$ precipitation events suggests that $P$ does not deviate strongly from being iid during this interval (Benestad 2003). However, these projections hinge on the assumption that the relationship between $m$ and the local $\bar{T}$ and $\bar{P}_{\mathrm{a}}$ is valid in the future.

Approach A yields interesting insight into the precipitation process by establishing the semi-exponential relationship. This relationship was also utilised by Approach B. For some locations, such as Bergen, the precipitation is associated with orographic forcing rather than the frontal or convective systems more commonplace in other parts of Europe. The fact that different large-scale physical processes are responsible for the production of rain in different regions may suggest that there is no universal relationship between rainfall and the local temperature, latitude or longitude. However, rainfall involves a high degree of stochastic character, which may follow a universal power-law behaviour (Malamud 2004). Whereas the orographic forcing is part of the macro-physical environment, micro-physical processes (such as cloud-drop growth through warm or cold initiation of rain) bring in a stochastic behaviour through diffusion processes in turbulent air spanning small to large spatial scales. Further cloud-drop growth through collision-andcoalescence and break-up of large cloud drops result in a cascading avalanche process that also adds to the stochastic behaviour (Rogers \& Yau 1989). Moreover, on the large scale, physical conditions affect the availability of moisture and set the stage for either warm or cold cloud-drop growth, thus affecting the cloud-drop growth rate, number, and phase. However, convective and orthographical cloud formation often involves the same micro-physical processes. The statistical analysis points to a very low probability that the relationship between the exponential coefficient and the local mean temperature and precipitation is due to chance, and the analysis suggests that the exponential law provides a good approximation for the precipitation amount distribution. Here, 2 independent approaches both provided support for this interpretation.

The analysis presented here is solely based on statistics, whereas Sapiano et al. (2006) proposed models based on physics. They explicitly included sea level pressure (SLP; $\partial p^{\prime} / \partial x$ ) and specific humidity $q_{\mathrm{s}}$ as predictors, and observed that the often neglected quantity $\partial T / \partial y$ is important for large-scale vertical motion. However, it is unclear how this predictor would relate to the exponential slope $m$ of a distribution for the local mean conditions. Since the present analysis involves stations at different altitudes, there are further uncertainties due to topographical effects and lapse rates, and due to large variations in the surface altitude on the spatial scales used here. In the present analysis, $\bar{T}$ and $\bar{P}_{\mathrm{a}}$ represent only some of the physical elements relevant for the local climate, but it is thought that SLP and humidity will not improve the description of the local conditions significantly. The reason why a change in the mean SLP will not contribute much to the predictive skill of precipitation is that it is a smooth field, whereas precipitation lacks the large-scale spatial coherence (Frich et al. 2002, Klein Tank \& Können 2003, 
Alexander et al. 2005, Achberger \& Chen 2006). Furthermore, this paper focuses on geographical, rather than temporal, variations. The SLP can often capture temporal fluctuations in temperature and precipitation due to anomalous advection, however, the mean local conditions are already implicitly taken into account through $\bar{T}$ and $\bar{P}_{\text {a }}$. Humidity is not used as it is not readily available (network of radiosondes not very dense), and the quality of the observations is not regarded as high as for temperature and precipitation, neither in models nor observations. However, $\bar{P}_{\mathrm{a}}$ does involve the atmospheric humidity indirectly.

Ferro et al. (2005) found that changes in scale $(\sigma)$ of the precipitation distributions predicted by the HIRHAM4 RCM (Christensen et al. 1998) from 1961-1990 to 2071-2100 can explain many differences over northern Europe. They compared the scale and shape parameters of the functions describing the PDF, $F\left(\sigma Z^{\alpha}\right)$, thus analysing transformed variables. In the present study, no transformation has been made, but the logarithm has been taken of the counts in each bin containing the number of events with precipitation amount within the bin's interval. Thus, the slope $m$, which reflects the number of events as a function of rainfall amount, is distinct from the shape parameter $\alpha$ employed by Ferro et al. (2005), and which explained few of the differences between the simulated present-day conditions and the scenario precipitation. Ferro et al. (2005) also estimated a change in the proportions of number of wet days over Fennoscandia in the range $-15 \pm 20 \%$, which implies a greater range than the present results.

Groisman et al. (2005) found a disproportionate change in heavy precipitation compared to the change in the mean. Here, both $N_{\mathrm{R}}$ and $\hat{m}$ are sensitive to the mean precipitation. The results presented here are in accord with Groisman et al. (2005), as the present analysis implies that higher percentiles will respond more strongly to a shift in the location. Equation (1) can illuminate the relationship between changes in the mean and extreme precipitation, if it can be assumed that the number of wet days $\left(N_{\mathrm{R}}\right)$ is constant. Then, if the mean value changes as $\Delta \mu=-\left(1 / m_{2}\right)+$ $\left(1 / m_{1}\right)$, percentile changes as $\Delta q_{p}=\left\{[\ln (1-p)] / m_{2}\right\}-$ $\left\{[\ln (1-p)] / m_{1}\right\}$, and $p>0.63$, then $|\ln (1-p)|>1$, and the percentile is more sensitive to changes in $m$ than the mean. Räisänen (2005) analysed results from the coupled inter-comparison project (CMIP2), which involved contributions from 20 different global climate models forced with $1 \%$ increased greenhouse concentrations per year. Since he focused on monthly and annual time scales, his results are not directly comparable to the results presented here, although the upper tails of monthly and daily distribution may be somewhat related. One conclusion of that study was that extremes on longer time scales are highly correlated with changes in the long-term mean precipitation, in contrast to $24 \mathrm{~h}$ extremes. He also observed that the large-scale geographical patterns of simulated fractional changes in the annual, seasonal and monthly maximum precipitation tend to scale with changes in the mean, although there may be differences in some of the regional details. The general picture according to CMIP2 was wetter future conditions over northern Europe and the Nordic countries. This finding is in agreement with previous analysis of monthly precipitation scenarios based on SRES A1b, suggesting more record-breaking events (compared to the same month in previous years) over northern Europe in the future (Benestad 2006), and is also consistent with the results from the present analysis. An interesting question, which is beyond the scope of this paper, is whether the change in the intensive precipitation is of cyclonic origin or due to convective systems. The implications of the former could be that intensified heavy precipitation could be an independent indication of more powerful storms, as the precipitation is the product of the energy transformation in the storms.

The results presented here are in rough agreement with the general picture given by Frei et al. (2006), who examined RCM simulations representing the 20712100 period forced by only one GCM (HadAM3H; Hudson \& Jones 2002) following the SRES A2 scenario as opposed to the SRES A1b. Frei et al. (2006) found a strong response in the extreme behaviour, as the present-day 40 to $100 \mathrm{yr}$ events were found to have a $20 \mathrm{yr}$ return interval in 2071-2100. The return interval associated with $q_{0.999}$ for daily data is $f=365.25 / 1000 \rightarrow \tau=$ $2.7 \mathrm{yr}$. The proportional change in the probability for exceeding $q_{0.999}$ for the analysis presented here was estimated according to

$\operatorname{Pr}\left(P^{*}>q_{0.999}\right) / \operatorname{Pr}\left(P>q_{0.999}\right)=100 \frac{\frac{N_{\mathrm{R}}^{*}}{365.25} \mathrm{e}^{m * q_{0.999}}-\frac{N_{\mathrm{R}}}{365.25} \mathrm{e}^{m q_{0.999}}}{\frac{N_{\mathrm{R}}}{365.25} \mathrm{e}^{m q_{0.999}}}$

employing Eq. (1), and the results suggested values as high as $35 \%$ in some places (not shown). Hence, the change in probability implies that a return interval of 2.7 at the present will be $\sim 2 \mathrm{yr}$ in 2050 . One should keep in mind that the return intervals of several years represent values further out in the tails of the PDFs where the exponential distribution does not fit the data closely (Fig. 2).

Räisänen (2005) also discussed the relationship between changes in the frequency of occurrence exceeding a critical threshold value for monthly precipitation and changes in magnitude, and observed a non-linear relationship with the relative frequency being more sensitive than extreme precipitation amounts. If the critical threshold is taken as the percentile $q_{\mathrm{c}}=\ln (1-p) /$ $m_{c}$ the magnitude of the extreme events $q_{p}^{+}=\ln (1-p) / m$, 
and $\operatorname{Pr}($ wet) from Eq. (3) is constant, then the framework used here can be utilised to examine the relationship between the magnitude and frequency. By allowing the value of $m$ to vary, the relation of $q_{p}^{+} / q_{\mathrm{c}}$ to $\mathrm{e}^{m q_{\mathrm{c}}} / \mathrm{e}^{m_{\mathrm{c}} q_{\mathrm{c}}}$ is a non-linear function $f(m)=\left(m_{\mathrm{c}} \mathrm{e}^{m_{\mathrm{c}} q_{\mathrm{c}}}\right) /$ $\left(m \mathrm{e}^{m q_{c}}\right)$ for which some solutions describe a stronger response in the relative change of probability than to the relative amplitude change. Thus, the non-linear relationship that Räisänen found for the longer timescales may appear to hold for the higher percentiles for daily precipitation, which also is consistent with the changes inferred from Fig. 4c,d. For the regions with high mean precipitation, these results are also consistent with one of the conclusions in Klein Tank \& Können (2003) that 'at stations where the annual amount increases, the index that represents the fraction of the annual amount due to very wet days gives a signal of disproportionate large changes in the extremes' (Klein Tank \& Können 2003, p. 3665).

Southern Europe may experience an increase in extremes but also a decrease in mean precipitation (Groisman et al. 2005). Such a scenario is in principle possible with Eqs. (4) \& (5) if the contribution from increased mean temperature is greater than that of a reduction in the mean precipitation.

Voss et al. (2002) observed that the description of the annual precipitation cycle in the ECHAM4 climate model (Roeckner et al. 1996) has the wrong phase over northern and central Europe. Such discrepancies justifies the use of ESD. On the other hand, assuming the precipitation followed a gamma distribution, they estimated an increase in $q_{0.95}$ by $\sim 20 \%$, and estimated the pattern correlation between the scale parameter $\beta$ for fitted gamma functions (Wilks 1995) and $q_{0.95}$ in a highresolution GCM experiment to be 0.71 (Voss et al. 2002). Thus, independently supporting the approach proposed here, albeit assuming a different distribution shape.

\section{CONCLUSIONS}

Climate change usually implies a change in the PDF and can be regarded as a case of so-called nonstationarity. Here, ESD of global state-of-the-art IPCC AR4 climate simulations has been employed to infer changes in the PDFs for $24 \mathrm{~h}$ precipitation, and a framework for analysing upper percentiles has been presented. The main results point to increased probabilities for $24 \mathrm{~h}$ precipitation in western coastal areas, southern Scandinavia, the British Isles and the northern parts of the European continent exceeding the present-day 95th percentile in 2050, given global climate change. However, the results are sensitive to the choice of predictors used to map the results.
Acknowledgements. This work was done under the Norwegian Regional Climate Development under Global Warming (RegClim) programme, and was supported by the Norwegian Research Council (Contract NRC-No. 120656/720) and the Norwegian Meteorological Institute. Eirik Førland and Jan Erik Haugen gave valuable comments on the manuscript. I acknowledge the international modelling groups involved with the climate change simulations for the IPCC AR4 for providing their data for analysis, the Program for Climate Model Diagnosis and Inter-comparison (PCMDI) for collecting and archiving the model data, the JSC/CLIVAR Working Group on Coupled Modelling (WGCM) and their Coupled Model Inter-comparison Project (CMIP) and Climate Simulation Panel for organising the model data analysis activity, and the IPCC WG1 TSU for technical support. The IPCC Data Archive at Lawrence Livermore National Laboratory is supported by the Office of Science, US Department of Energy. The analysis was carried out using the free software packages Ferret (http://ferret.wrc.noaa.gov/Ferret/) and R (http://cran. r-project.org). I am also grateful to Inger Hanssen-Bauer for comments on the paper.

\section{LITERATURE CITED}

Achberger C, Chen D (2006) Trend of extreme precipitation in Sweden and Norway during 1961-2004. Research report C72. Earth Sciences Centre, Gothenberg. Göteborg University

Alexander L, Zhange X, Peterson T, Caesar J and 20 others (2005) Global observed changes in daily climate extremes of temperature and precipitation. J Geophys Res 111(D5), doi: 10.1029/2005JD006290

Barnett T, Zwiers F, Hegerl G, Allen M and 9 others (1999) Detecting and attributing of recent climate change: a status report. Bull Am Meteorol Soc 80:2631-2659

Barnett TP (1999) Comparison of near-surface air temperature variability in 11 coupled Global Climate Models. J Clim 12:511-518

Benestad RE (2001) A comparison between two empirical downscaling strategies. Int J Climatol 21:1645-1668, doi: 10.1002/joc.703

Benestad RE ( 2003) How often can we expect a record event? Clim Res 25:3-13

Benestad RE (2004a) Empirical-Statistical Downscaling in climate modeling. Eos Trans Am Geophys Union 85(42): 417,422

Benestad RE (2004b) Record-values, non-stationarity tests and extreme value distributions. Global Planet Change 44: 11-26, doi:10.1016/j.gloplacha.2004.06.002

Benestad RE (2004c) Tentative probabilistic temperature scenarios for northern Europe. Tellus Ser A Dyn Meterol Oceanogr 56:89-101

Benestad RE (2005) Climate change scenarios for northern Europe from multi-model IPCC AR4 climate simulations. Geophys Res Lett 32: L17704, doi:10.1029/2005GL023401

Benestad RE (2006) Can we expect more extreme precipitation on the monthly time scale? J Clim 19:630-637

Benestad RE, Chen D (2006) The use of a calculus-based cyclone identification method for generating storm statistics. Tellus Ser A Dyn Meterol Oceanogr 58:473-486, doi:10.1111/j.1600-0870.2006.00191.x

Benestad RE, Achberger C, Fernandez E (2005) Empiricalstatistical downscaling of distribution functions for daily precipitation. Met.no report 12/2005. Meterologisk Institutt, Oslo. Available from: http://met.no/english/r_and_d_ activities/publications/2005/12_2005/abstract_12_2005.html 
Christensen JH, Christensen OB (2002) Severe summertime flooding in Europe. Nature 421:805-806

Christensen B, Christensen JH, Machenhauer B, Botzet M (1998) Very high-resolution climate simulations over Scandinavia - present climate. J Clim 11:3204-3229

Ferro CAT, Hannachi A, Stephenson DB (2005) Simple nonparametric techniques for exploring changing probability distributions of weather. J Clim 18:4344-4354

Frei C, Schär C (2001) Detection of trends in rare events: theory and application to heavy precipitation in the Alpine Region. J Clim 14:1568-1584

Frei C, Schöll R, Fukutome S, Schmidli J, Vidale PL (2006) Future change of precipitation extremes in Europe: intercomparison of scenarios from regional climate models. J Geophys Res 111:D06105, doi:10.1029/2005JD005965

Frich P, Alexander L, Della-Marta P, Gleason B, Haylock M, Klein Tank AMG, Peterson T (2002) Observed coherent changes in climatic extremes during the second half of the twentieth century. Clim Res 19:193-212

Groisman PY, Knight RW, Easterling DR, Karl TR, Hegerl GC, Razuvaev VN (2005) Trends in intense precipitation in the climate record. J Clim 18:1326-1350

Hayhoe K, Cayan D, Field CB, Frumhoff PC and 15 others (2004) Emission pathways, climate change, and impacts on California. Proc Natl Acad Sci USA 101:12422-12427

Hudson DA, Jones RG (2002) Simulations of present-day and future climate over southern Africa using HadAM3H. Hadley Centre Technical Note 38. Met Office, Hadley Centre for Climate Prediction and Research, Bracknell

Hundecha Y, Bárdossy A (2005) Trends in daily precipitation and temperature extremes across western Germany in the second half of the 20th century. Int J Climatol 25: 1189-1202

Klein Tank AMG, Können GP (2003) Trends in indices of daily temperature and precipitation extremes in Europe, 1946-99. J Clim 16:3665-3680, doi:10.1175/1520-0442

Klein Tank AMG, Wijngaard JB, Können GP, Böhm R and 36 others (2002) Daily dataset of 20th-century surface air temperature and precipitation series for the European Climate Assessment. Int J Climatol 22:1441-1453. Data and metadata available from: http://eca.knmi.nl

Leroy SS (1998) Detecting climate signals: some Bayesian aspects. J Clim 11:640-651

Lorenz EN (1956) Empirical orthogonal functions and statistical weather prediction. Sci Rep 1. Department of Meteorology, Massachusetts Institute of Technology, Cambridge, MA

Malamud BD (2004) Tails of natural hazards. Physics World 2004(Aug):31-35

Matheron G (1963) Principles of geostatistics. Econ Geol 58: 1246-1266

Palmer TN, Räisänen J (2002) Quantifying the risk of extreme seasonal precipitation events in a changing climate. Nature 415:512-514

Pryor SC, School JT, Barthelmie RJ (2005) Climate change impacts on wind speeds and wind energy density in northern Europe: empirical downscaling of multiple AOGCMs. Clim Res 29:183-198

Pryor SC, School JT, Barthelmie RJ (2006) Winds of change? Projections of near-surface winds under climate change scenarios. Geophys Res Lett 33, doi:10.1029/2006GL026000

R Development Core Team (2004) R: A language and environment for statistical computing. R Foundation for Statistical Computing, Vienna, Austria

Räisänen J (2005) Impact of increasing $\mathrm{CO}_{2}$ on monthly-toannual precipitation extremes: analysis of the CMIP2 experiments. Clim Dyn 24:309-323

Roeckner E, Arpe K, Bengtsson L, Christof M and 6 others (1996) The atmospheric general circulation model ECHAM4: model description and simulation of presentday climate. MPI Tech Rep 218. Max-Planck-Institute für Meteorologie, Hamburg

Rogers RR, Yau MK (1989) A short course in cloud physics, 3rd edn. Pergamon Press, Oxford

Sapiano MRP, Stephenson DB, Grubb HJ, Arkin PA (2006) Diagnosis of variability and trends in in a global precipitation dataset using a physically motivated statistical model. J Clim 19(7):4154-4166, doi: 10.1175/JCL3849.1

Schmidli J, Frei C (2005) Trends of heavy precipitation and wet and dry spells in Switzerland during the 20th century. Int J Climatol, 25:753-771 doi: 10.1002/joc.1179

Simmons AJ, Jones PD, da Costa Bechtold V, Beljaars ACM and 5 others (2004) Comparison of trend and variability in CRU, ERA40 and NCEP/NCAR analyses of monthly-mean surface air temperatures. ERA40 Project Rep Ser 18. Eur Cent Medium-Range Weather Forcasts, Reading

von Storch H (1999) On the use of 'inflation' in statistical downscaling. J Clim 12:3505-3506

Voss R, May W, Roeckner E (2002) Enhanced resolution modelling study on anthropogenic climate change: changes in extremes of the hydrological cycle. Int $\mathrm{J}$ Climatol 22: $755-777$

Wijngaard JB, Klein Tank AMG, Können GP (2003) Homogeneity of 20th century daily temperature and precipitation series. Int J Climatol 23:679-692

Wilks DS (1995) Statistical methods in the atmospheric sciences. Academic Press, Orlando, FL

Yan Z, Bate S, Chandler RE, Isham V, Wheater H (2006) Changes in extreme wind speeds in NW Europe simulated by generalized linear models. Theor Appl Clim 83: 121-137

Yang C, Chandler RE, Isham VS, Wheather HS (2005) Spatialtemporal rainfall simulation using generalized linear models. Water Resour Res 41, doi: 10.1029/2004WR003739 
Appendix 1. Name of locations from which daily data were used to calibrate Eq. (5) and for independent evaluation of Eqs. (1) and (5). The calibration data are referred to as 'Dependent' and the validation data as 'Independent'

\begin{tabular}{|ll|}
\hline Dependent & Independent \\
\hline Armagh & Beograd \\
Bergen & Birr \\
Bjørnøya & Bologna \\
Bodø & Borkenes \\
Bourges & Buchuresti \\
Braganca & Copenhagen \\
Brindisi & Dividalen \\
Cagliari & Dublin \\
Corfu & Fagernes \\
De Bilt & Falun \\
Drevsjø & Ferder \\
Fagernes & Fiskåbygd \\
Fokstua & Geneve \\
Glomfjord & Halten Fyr \\
Hellinikon & Hull \\
Helsinki & Jyväskylä \\
Heraklion & Karlstad \\
Karasjok & Ljubljana \\
Kjøremsgrende & Lugano \\
Linkøping & Malin Head \\
Lisboa & Nordby \\
Malaga & Orkdal \\
Marseille & Östersund \\
Møsstrand & Saltdal \\
Ny-Ålesund & Sklinna Fyr \\
Örland & St. Petersburg \\
Oslo & Tirana \\
Oxford & Tranebjerg \\
Porto & Værnes \\
Prestebakke & Växjö \\
Reykjavik & Vardø \\
Roma & Venabu \\
Salamanca & Vigra \\
San Sebastian & Vilnius \\
Sihcajavri & Vilsandi \\
Sirdal & Vinger \\
Skåbu & Wick \\
Sodänkylä & \\
Sonnblick & \\
Stensele & \\
Svalbard & \\
Svinøy & \\
Torrevieja & \\
Toulouse & \\
Tromsø & \\
Vtsira & \\
Veroncia & \\
Wien & \\
\hline
\end{tabular}

Appendix 2. Empirical-statistical downscaling (ESD)

The empirical-statistical downscaled results were obtained using a common empirical orthogonal function framework described in Benestad (2005) auxiliary material. The ESD was implemented using a tool called clim.pact v.2.1-5 (Benestad 2004a), written for the R-environment ( $\mathrm{R}$ Development Core Team 2004), a package that is open source and freely available from CRAN (http://cran.r-project.org).

The predictor used for calibrating ESD models for the local $T$ was the monthly mean large-scale $T$ anomalies from the ERA40 re-analyses (Simmons et al. 2004), and the corresponding predictor for local $P$ was the total $P$ from the ERA40. The ESD analysis selected the predictor domain on an individual station basis, based on the criterion that the predictor region should only encompass the region where the large-scale anomaly field is positively correlated with the local variable (Benestad 2004a). Once the domain was selected for a location, the GCM results were interpolated to the observed (here ERA40 re-analysis) grid for the same domain, and the anomalies from the GCM results were combined with those of ERA40. Then an empirical orthogonal function (EOF) (Lorenz 1956) analysis was applied to the combined data set (common EOF; Barnett 1999), and the EOF products were used for ESD model calibration and prediction. This method is evaluated and described in further detail by Benestad (2001). The observations were de-trended prior to model calibration and a stepwise screening using the Akaike information criterion (AIC; Wilks 1995, p. 301-302) was used to exclude non-important principal components and hence avoid over-fitting. In clim.pact, this objective downscaling approach is done through the function objDS (Benestad 2004a). The downscaling was applied separately to single series for one given station and a given calendar month. The annual series for each location was constructed from 12 individual downscaling exercises in order to represent all calendar months. The downscaled results were not subject to 'inflation' (von Storch 1999).

In order to ensure that the observed spatial patterns dominate the EOF products, the GCM data were scaled (multiplication with $0.25 \times n_{1} / n_{2}$, where $n_{1}$ is the ERA40 record length and $n_{2}$ the GCM record length) prior to the EOF analysis, and subsequently re-scaled to describe the original variance before the stepwise regression analysis. The motivation for using a scaling factor of 0.25 is to avoid splitting the ERA40 and GCM into different modes (principal components) if the spatial structures differ substantially.

The ESD analysis incorporated a form of quality control by requiring similar spatial structures on anomalies in the observations and the GCM and is described in more detail in the auxiliary material of Benestad (2005). The end result is in essence a weighted ensemble mean of the ESD results for the SRES A1b scenario derived from the super ensemble consisting of 23 different GCM scenarios for $T$ and 21 for $P$. Annual mean trends have been derived for $T$ and $P_{\mathrm{a}}$ for each station location using a Bayesian-type approach (Wilks 1995, Leroy 1998, Barnett et al. 1999) based on 21 different GCM simulations for precipitation and 23 for temperature, where the individual GCMs were weighted according to a set of grades given on their performance (Benestad 2005). The downscaled scenarios used here are available from ftp://ftp.agu.org/apend/gl/ 2005 GL023401. 
Appendix 3. Name of locations from which daily data were used for gridding $\bar{T}$ and gridding $\bar{P}_{\mathrm{a}}$, respectively

\begin{tabular}{|c|c|c|c|c|c|c|c|c|}
\hline Station & $\bar{T}$ & $\bar{P}_{\mathrm{a}}$ & Station & $\bar{T}$ & $\bar{P}_{\mathrm{a}}$ & Station & $\bar{T}$ & $\bar{P}_{\mathrm{a}}$ \\
\hline Abisko & + & + & Junsele & & + & Reykjavik & + & + \\
\hline Akureyri & + & + & Jyväskylä & + & + & Rochefort & & + \\
\hline Ammasalik & + & + & Kajaani & + & + & Roches Point & + & + \\
\hline Ath & & + & Kalmar & + & + & Scoresbysund & + & + \\
\hline Bergen-Flor. & + & + & Karasjok & + & + & Ship M & + & \\
\hline Bergen-Fred. & + & & Karesuando & + & + & Sidsjö & & + \\
\hline Birr & + & + & Karlstad & + & + & Sint-Andries-Brugge & & + \\
\hline Bjørnøya & + & + & Kirkwall & + & + & Skjåk & & + \\
\hline Borås & + & + & Kjøremsgrendi & + & & Sodankylä & + & + \\
\hline Braemar & + & + & København & + & + & Sösjö & & + \\
\hline Chimay & & + & Krokshult & & + & Stavelot & & + \\
\hline Chiny & & + & Kråkmo & & + & Stensele & + & + \\
\hline Danmarkshavn & + & + & Kuopio & + & + & Stockholm & + & + \\
\hline De Bilt & + & + & Kuusamo & + & + & Stornoway & + & + \\
\hline De Kooy & + & & Kvikkjokk & + & + & Stykkisholmur & + & + \\
\hline Dumfries & + & + & Lærdal & + & & Svalbard & + & \\
\hline Edinburgh & + & + & Landsort & + & + & Sveg & + & + \\
\hline Eelde & + & & Lappeenranta & + & + & Svenska Högarna & + & + \\
\hline Falsterbo & + & & Leipikvattnet & & + & Tampere & + & + \\
\hline Falun & + & + & Leopoldsburg & & + & Tärnaby & + & \\
\hline Ferder & + & & Lerwick & + & + & Tasiilaq & + & + \\
\hline Gembloux & & + & Lien-Selbu & & + & Teigarhorn & + & + \\
\hline Glomfjord & + & + & Lisjø & & + & Thimister & & + \\
\hline Godthaab & + & + & Løvånger & & + & Tjåmotis & & + \\
\hline Göteborg & + & + & Maastricht & + & & Torshavn & + & + \\
\hline Gotska Sandön & + & + & Malin Head & + & + & Tranebjerg & + & + \\
\hline Grængesberg & & + & Malung & & + & Tromsø & + & + \\
\hline Halden & & + & Maredsous & & + & Turku & + & + \\
\hline Haell & + & & Markree Castle & & + & Uccle & + & \\
\hline Härnösand & + & & Mestad & & + & Upernavik & + & + \\
\hline Halmstad & + & + & Narsarsuaq & + & + & Uppsala & + & + \\
\hline Hammerodde & + & + & Nedstrand & & + & Utsira & + & \\
\hline Haparanda & + & + & Nesbyen & + & & Vänersborg & & + \\
\hline Håvelund & & + & Nordby & + & + & Værnes & + & + \\
\hline Havraryd & & + & Nuuk & + & + & Växjö & + & + \\
\hline Helsinki & + & + & Öland & + & & Valentia obs. & + & \\
\hline Hives & & + & Ørskog & & + & Vardø & + & \\
\hline Hoburg & + & + & Östersund & + & + & Vestervig & + & + \\
\hline Holmögadd & + & + & Oksøy & + & + & Vestmannaeyjar & + & + \\
\hline Hopen & + & & Ona & + & & Vetti & & + \\
\hline Ilulissat & + & & Oslo-Blind. & + & + & Vinga & + & + \\
\hline Ittoqqortoormiit & + & + & Oulu & + & + & Visby & + & + \\
\hline Ivigtut & + & + & Phoenix Park & + & + & Vlissingen & + & \\
\hline Jakobshavn & + & + & Piteå & + & + & Wick & + & + \\
\hline Jan Mayen & + & + & Raufarhoefn & + & + & & & \\
\hline Jokkmokk & + & + & Reinli & & + & & & \\
\hline
\end{tabular}

Appendix 4. Analytical expression for relationship between $m$ and $\bar{P}_{\mathrm{w}}$

An analytical expression for the mean value of wet day precipitation $\left(\bar{P}_{\mathrm{w}}\right)$ can be derived by employing integration by parts:

$$
\begin{aligned}
\bar{P}_{W} & =\int_{x=0}^{\infty}-m x \mathrm{e}^{m x} \mathrm{~d} x=-m\left(\left[\frac{x}{m} \mathrm{e}^{m x}\right]_{0}^{\infty}-\int_{x=0}^{\infty} \frac{1}{m} \mathrm{e}^{m x} \mathrm{~d} x\right)_{0}^{q_{p}} \\
& =m\left[\frac{\mathrm{e}^{m x}}{m^{2}}\right]_{0}^{\infty} \rightarrow \bar{P}_{W}=-\frac{1}{m} m<0
\end{aligned}
$$

Appendix 5. Derivation of the analytical expression for the percentile

The expression for the percentiles can be found analytically by solving the integral over the PDF:

$p=\int_{x=0}^{q_{p}}-m \mathrm{e}^{m x} \mathrm{~d} x=\left[\mathrm{e}^{m x}\right]_{0}^{q_{p}}=-\mathrm{e}^{m q_{p}}+1 m<0 \rightarrow q_{p}=\frac{\ln (1-p)}{m}$ 
Appendix 6. Mapping

Multi-model ensemble weighted mean linear trends $\mathrm{d} T / \mathrm{d} t$ for annual mean values over the period 2000-2099 were estimated for each station location, thus providing a quality-weighted trend estimate. The gridding technique used in the Benestad (2005) study used the square-root distance from the coast $(\sqrt{d})$ and included the 4 additional geographical predictors: zonal distance, meridional distance (in units of $10 \mathrm{~km}$ ), north-south slope and east-west slope. The differentiation is described in more detail in the auxiliary material of Benestad (2005), and was carried out in the Renvironment, using the geoGrad function in the contributed cyclones-package (v.1.1-4) described in Benestad \& Chen (2006), an open source code that is freely available from http://cran.r-project.org.

The regression of the weighted mean ESD results $\mathrm{d} T / \mathrm{d} t$ against geographical parameters obtained $\mathrm{R}^{2}$ of $66 \%$ for the annual mean $T$ trends (an $F$-ratio of 32.2 and a p-value of $5 \times$ $\left.10^{-15}\right)$, indicating a strong relationship. Extrapolations of $\mathrm{d} T / \mathrm{d} t$ based on this regression analysis were then used together with values for present-day conditions to provide gridded estimates for $\bar{T}^{*}=\bar{T}+\Delta T$ in year 2050. The corre- sponding statistical relationship obtained for $P$ against the geographical parameters was weaker, however, still statistically significant to a high degree: $33 \%$ of the $P$ trends, $F$ ratio $=10.8$, and a $p$-value of $4 \times 10^{-7}$. Thus, the value of $\bar{P}_{\mathrm{a}}$ is underestimated unless the residual is accounted for.

A kriging analysis (Matheron 1963) was applied to the residuals of the regression analysis in order to spatially interpolate the part of the trends that could not be related to geographical parameters (using the geoR package for R). Hence, the maps represent more than just the geographical variance accounted for by the multiple regressions used for geographical modelling, since interpolated residuals are added to the prediction to recover most of the signal. Kriging is a standard method used for spatial interpolation in geo-sciences, and an evaluation of the kriging methodology is outside the scope of this paper. The mapping analysis used east-west and north-south displacements from the central point of the set of locations (in units of $10 \mathrm{~km}$ ) rather than longitude and latitude. Due to the Earth's curvature, a difference of one degree at high latitudes corresponds to a smaller zonal displacement than at lower latitudes.
Editorial responsibility: Bryson Bates, Wembley, Western Australia, Australia
Submitted: September 13, 2006; Accepted: June 4, 2007 Proofs received from author(s): August 27, 2007 